\title{
Inhibition of proliferation, migration and invasion of human non-small cell lung cancer cell line A549 by phlomisoside $F$ from Phlomis younghusbandii Mukerjee
}

\author{
Xiao-xian Lu, Xiao-xia Ji, Jie Bao, Qian-qian Li, Dan-dan Ji and Liang Luo* \\ Intensive Care Units, The Second People's Hospital of Wuxi City, Wuxi 214002, China
}

*For correspondence: Email: doctorluoliang@126.com; Tel/Fax: +86-0510-66681023

Received: 10 November 2015

Revised accepted: 8 June 2016

\begin{abstract}
Purpose: To determine the effect of phlomisoside $F(P M F)$ on the proliferation, migration and invasion of human non-small cell lung cancer cell line A549 and explore the possible mechanisms.

Methods: The anti-proliferative effect of PMF on A549 cells was determined by CCK-8. Subsequently, migration and invasion were evaluated by Transwell and Transwell with matrigel assays, respectively. Furthermore, cell cycle and apoptosis were assessed by flow cytometry, while the mechanisms of action were determined by Western blotting.

Results: PMF exhibited significant anti-proliferative effect on A549 cells in concentration-dependent and time-dependent manners, with half maximal inhibitory concentration $\left({ }^{\prime} C_{50}\right)$ of $54.51 \mu M$. Treatment with PMF (10,20 and $40 \mu \mathrm{M})$ for $48 \mathrm{~h}$ resulted in significantly decreased migration and invasion in $A 549$ cells. In addition, PMF at concentrations of 25, 50 and $75 \mu \mathrm{M}$ induced cell cycle arrest in G0/G1phase and enhanced cell apoptosis in A549 cells. Furthermore, caspase-3, caspase-9 and Bax protein expressions were up-regulated while Bacl-2 and COX-2 protein expressions were significantly downregulated at 10,20 and $40 \mu M$ concentrations of PMF.

Conclusion: PMF suppresses A549 cell growth, migration and invasion. The mechanism may be related to the induction of mitochondria-mediated apoptosis pathway via regulation of caspase-3, caspase-9, Bcl-2 and Bax expressions, and inhibition of $P_{G} E_{2}$ synthesis by reducing COX-2 expression.
\end{abstract}

Keywords: Phlomisoside F, Lung cancer, Cell mobility, Apoptosis, PGE 2 , COX-2 expression, Caspase, Cell cycle arrest

Tropical Journal of Pharmaceutical Research is indexed by Science Citation Index (SciSearch), Scopus, International Pharmaceutical Abstract, Chemical Abstracts, Embase, Index Copernicus, EBSCO, African Index Medicus, JournalSeek, Journal Citation Reports/Science Edition, Directory of Open Access Journals (DOAJ), African Journal Online, Bioline International, Open-J-Gate and Pharmacy Abstracts

\section{INTRODUCTION}

Lung cancer is the most common cancer in males with increasing incidence and mortality, and is the leading cause of cancer-related deaths in China [1]. Scientific data has clearly shown that the dominant risk factor of lung cancer is tobacco exposure and approximately $60-70 \%$ of lung cancer patients are ever-smokers in China [2]. In addition, the most common type of lung cancer is non-small cell lung cancer
(NSCLC) which has high rates of unknown disease stage at diagnosis [3]. Although researchers have made progress in the treatment of lung cancer, current treatment modalities are still inadequate and there is no cure. Therefore, an effective therapeutic method is still urgently needed to reduce the incidence and improve the survival of Chinese lung cancer patients. 
Phlomis younghusbandii Mukerjee (Lamiaceae) is a perennial herbal plant, which is often found in the grassland of hillsides, meadows and riverbeaches in Qinghai-Tibet Plateau [4]. Importantly, the aerial part of this plant has been used as a kind of Tibetan conventional medicine for thousands of years in China [5]. $P$. younghusbandii has been widely used in clinical treatment and has various pharmacological activities, such as treating lung disease, colds and coughs, bronchitis and throat disease [5,6]. However, research and study on modern pharmacology of $P$. younghusbandii is not common. Over the years, several studies demonstrated that the root extracts of $P$. younghusbandii had anti-bacterial, analgesic and anti-inflammatory activities [7-9]. But whether the extracts or chemical components from Phlomis younghusbandii have anti-cancer activity has not been reported up to now.

Phlomisoside F (PMF), a furanolabdane diterpene glycoside, is from the ethyl acetate extract of $P$. younghusbandii root, which has been reported in previous studies [10,11]. Previous data indicated that PMF has significant anti-inflammatory activity in vitro and in vivo [10]. In this study, PMF was isolated and identified from $P$. younghusbandii. Furthermore, the antilung cancer activity of PMF was investigated and the possible mechanism was explored in A549 cells, which may provide a scientific basis for its use in the traditional treatment of lung cancer.

\section{EXPERIMENTAL}

\section{Preparation of pure compounds}

$P$. younghusbandii was procured from Hehuachi Market of Traditional Chinese Herbs in 2014 and identified by a taxonomist at the Department of Traditional Chinese Medicine of our hospital. A voucher specimen of $P$. younghusbandii (201408-LL) was kept in our laboratory for future reference. PMF was isolated from the dry root of $P$. younghusbandii and characterized by a previously described method [11]. In brief, the dry root of $P$. younghusbandii $(10 \mathrm{~kg})$ was pulverized to prepare the extract. After reflux extraction with ethanol two times for $2 \mathrm{~h}$ each time, the extract was filtered and then the solvent was evaporated to get the ethanol extract of $P$. younghusbandii root under reduced pressure in a rotary evaporator. Further, the crude ethanol extract was dissolved in distilled water and then the suspension was successively treated with petroleum ether, ethyl acetate and n-butanol. Thereafter, five fractions $(\mathrm{I}-\mathrm{V})$ were obtained by using silica gel (200 - 300 mesh) column chromatography and eluting with trichloromethane - methyl alcohol (8:1). Finally, the compound was isolated from fraction III by using repeated silica gel column chromatography (200 - 300 mesh) and Sephadex LH - 20 chromatography. Additionally, the isolated compound, phlomisoside $F$, was identified based on the ${ }^{1} \mathrm{H}-\mathrm{NMR}$ and ${ }^{13} \mathrm{C}-\mathrm{NMR}$ data, which was consistent with previous data [11]. The chemical structure of PMF is shown in Figure 1.

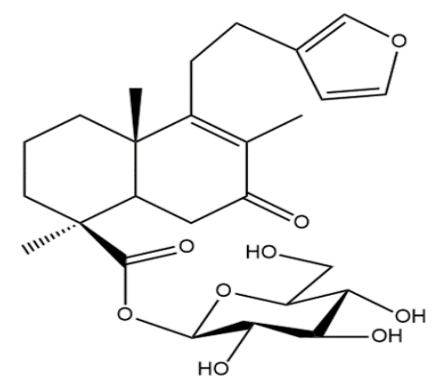

Figure 1: Chemical structure of phlomisoside $\mathrm{F}$

\section{Cell culture}

Human non-small cell lung cancer cell line A549 was purchased from Shanghai cell bank of Chinese Academy of Sciences (Shanghai, China) and cultured in RPMI - 1640 medium (Hyclone, Logan, UT) supplemented with $10 \%$ fetal bovine serum (FBS; Gibco, Grand Island, USA) and antibiotics (100 U/mL penicillin $\mathrm{G}$ and $100 \mathrm{mg} / \mathrm{mL}$ of streptomycin) at $37{ }^{\circ} \mathrm{C}$ in a $5 \%$ $\mathrm{CO}_{2}$ humidified atmosphere.

\section{Cell proliferation assay by CCK-8}

Cellular proliferation was evaluated by Cell Counting Kit-8 (Beyotime, Jiangsu, China) following the manufacturer's protocol. In brief, 2 $\times 10^{3}$ cells per well were seeded in 96 -well plates and incubated with either vehicle (DMSO) or increasing concentrations of PMF. Cell proliferation was measured $48 \mathrm{~h}$ later and the absorbance was measured using a 96-well plate reader (Bio-Rad Laboratories, Shanghai, USA) at $450 \mathrm{~nm}$. Results were reported as a percentage of DMSO control cells. $I_{50}$ values represent the concentration at which cell growth was inhibited by $50 \%$. Furthermore, for determining the timedependent manner, A549 cells were treated with PMF $(50 \mu \mathrm{M})$ for $12,24,36,48$ and $72 \mathrm{~h}$, respectively; CCK-8 assay was used to determine cell proliferation inhibition.

\section{Cell cycle analysis and apoptosis assay by flow cytometry}

For cell cycle analysis, cells were cultured with either diluent control (DMSO) or various concentrations of PMF $(25,50$ and $75 \mu \mathrm{M})$ for 48 
$\mathrm{h}$, and then were treated with $0.25 \%$ trypsin to prepare the single cell suspension in phosphate buffered saline with $10 \%$ FBS. After that, cells were washed and fixed in $70 \%$ precooled ethanol. Finally, cells were stained by propidium iodide (PI)/RNase $A$ and measured by flow cytometry (FACS Calibur, BD Biosciences).

Annexin V - FITC Apoptosis Detection Kit (Beyotime, Jiangsu, China) was used to determine the effect of PMF on A549 cells apoptosis. After treatment with or without various concentrations of PMF $(25,50$ and $75 \mu \mathrm{M})$ for 48 $h$, cells were harvested and then were stained by annexin-V-fluorescein isothiocyanate (FITC) and $\mathrm{PI}$ according to the manufacturer's protocol. Subsequently, the apoptotic cells were measured on a FACS Calibur Flow Cytometer (BD Biosciences, San Jose, CA, USA). The cells apoptosis in early was only labeled by annexin $\mathrm{V}$ while the cells apoptosis in late was labeled by both annexin- $\mathrm{V}$ and $\mathrm{PI}$.

\section{In vitro invasion and migration assay}

Cell invasion abilities were assessed by transwell well culture chambers (Corning Incorporated Tewksbury, MA, USA) with matrigel (BD Biosciences, Shanghai, China). In brief, the lower chamber was filled with $0.75 \mathrm{~mL}$ of RPMI 1640 with $10 \%$ FBS. Then $0.5 \mathrm{~mL}$ of A549 cells with serum-free RPMI $1640\left(1 \times 10^{5}\right.$ cells/well $)$ were seeded in the upper chamber and treated with or without indicated PMF (10, 20 and $40 \mu \mathrm{M})$. After incubation for $48 \mathrm{~h}$ at $37{ }^{\circ} \mathrm{C}$ in $5 \% \mathrm{CO}_{2}$ atmosphere, the invaded cell was stained with hematoxylin-eosin solution and counted by the optical microscope (Olympus, Japan).

For transwell migration assay, the lower chambers were filed with RPMI 1640 medium with $10 \% \mathrm{FBS}$ and $5 \times 10^{4}$ cells with serum-free RPMI 1640 medium were seeded in the upper chamber with a non-coated transwell insert. And the subsequent steps were similar with the invasion experiment above. The migrated cells in the lower chamber were also stained with hematoxylin-eosin solution and observed by the optical microscope (Olympus, Japan).

\section{Western blotting}

Cells were harvested after treatment with various concentrations of PMF (10, 20 and $40 \mu \mathrm{M})$ for 48 h. Subsequently, cells were lysed by western blot \& IP cell lysis buffer (Beyotime, Jiangsu, China) and then the total protein was quantified by the BCA Protein Assay Reagent (Sangon Biotech, Shanghai, China).Equal amounts of protein (20 $\mu \mathrm{g}$ ) was loaded to the sodium dodecyl sulfate- polyacrylamide gel electrophoresis (SDS-PAGE) and transferred to nitrocellulose filter membrane. Then, the membrane was incubated with anticaspase-3 (1: 200), anti-caspase-9 (1: 200), antiBcl-2 (1: 200), anti-Bax (1: 200), anti-COX-2 (1: 200) and anti-GAPDH (1: 200) antibodies at $4{ }^{\circ} \mathrm{C}$ for $12 \mathrm{~h}$ followed by corresponding horseradish peroxidase-conjugated secondary antibodies. Finally the immunoreactive band was visualized with ECL-detecting reagents. The primary antibodies included rabbit caspase-3polyclonal antibody, rabbit caspase- 9 polyclonal antibody, rabbit $\mathrm{Bcl}-2$ polyclonal antibody, rabbit Bax polyclonal antibody, rabbit COX-2polyclonal antibody, and rabbit GAPDH polyclonal antibody, which were purchased from Santa Cruz Biotechnologies (Santa Cruz, CA). The secondary antibody was horseradish peroxidase-conjugated goat anti-rabbit IgG and was purchased from Wuhan Boster Biological Technology (Wuhan, China).

\section{Statistical analysis}

All Data was expressed as mean \pm standard deviation of three independent experiments and $p<0.05$ was considered statistically significant. Data analysis was carried out using SPSS 19.0 software package and one way analysis of variance (ANOVA) with Dunnett's test was used to compare the means between two groups.

\section{RESULTS}

\section{PMF inhibits proliferation of A549 cell in vitro}

The effect of PMF on A549 cell viability was detected by the CCK-8 assay. As shown in Figure $2 A$, the estimated $I_{50}$ of PMF was 54.51 $\mu \mathrm{M}$ in A549 cells. Compared with the vehicle group (DMSO group), PMF induced significant growth inhibition in concentration-dependent and time-dependent manners in $48 \mathrm{~h}$ (Figure 2B).

\section{PMF inhibits invasion and migration of A549 cell in vitro}

We confirmed the inhibitory effect of PMF on A549 cells invasion and migration by the matrigel invasion assay and the transwell migration assay in vitro, respectively. Fig. $3 A$ and $B$ showed the effect of PMF on A549 cells invasion and there is a significant difference between the control and PMF treated groups $(p<0.01)$. Furthermore, as shown in Figure 3C and D, PMF at 10, 20 and 40 $\mu \mathrm{M}$ also effectively inhibited lung cancer cell migration $(p<0.01)$. 
A

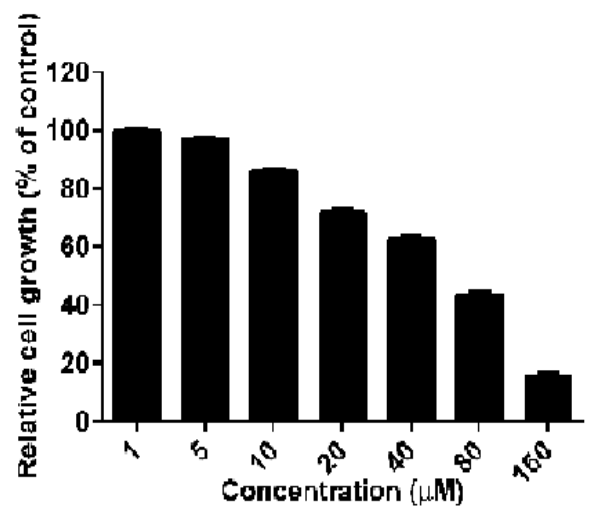

B

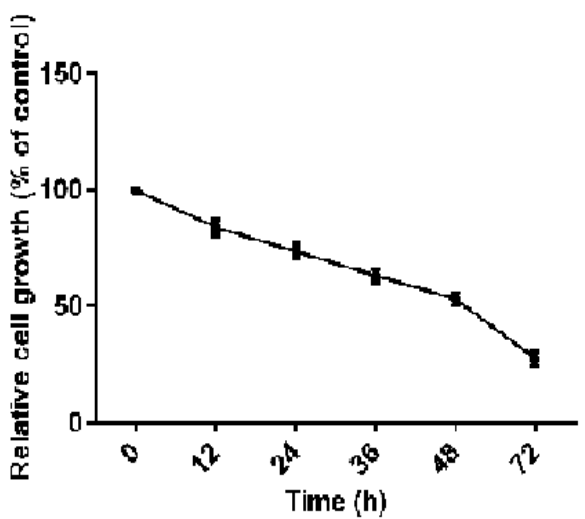

Figure 2: Effect of PMF on the growth of A549 cells. (A) After treatment with either vehicle (DMSO, negative control) or increasing concentrations of $\operatorname{PMF}(0,5,10,20,40,80$ and $160 \mu \mathrm{M}, 48 \mathrm{~h})$, cell proliferation was determined by CCK-8 assay. Concentration-response curve was plotted to determine $\mathrm{IC}_{50}$ values using the GraphPad Prism 5. (B) Cells were treated with PMF $(50 \mu \mathrm{M})$ and cell viability was analysed by CCK-8 assay at 0 , $12,24,36,48$ or $72 \mathrm{~h}$ Time-dependent curve was plotted to analyse the observed effect of PMF. Results represent the mean \pm SD of three independent experiments performed in triplicates; ${ }^{* *} p<0.01$, compared to the control group

A

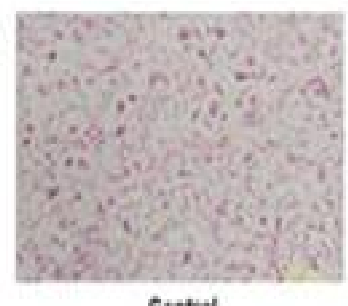

Coetred

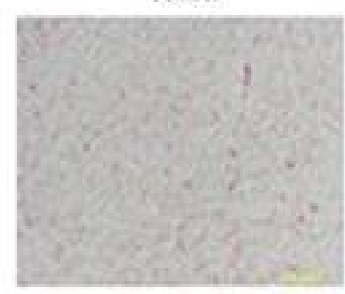

20 in

B

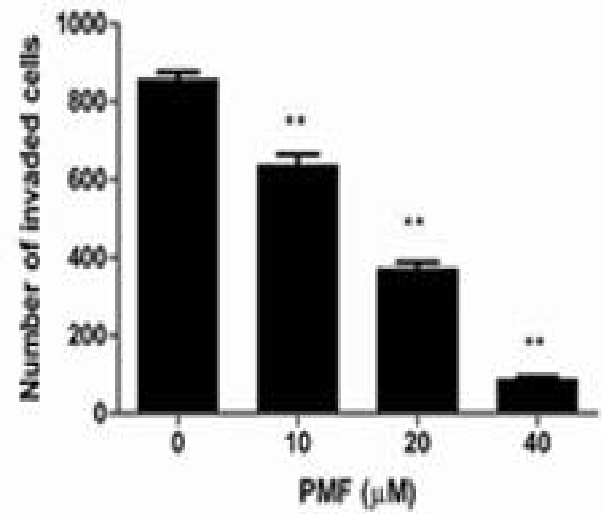

C

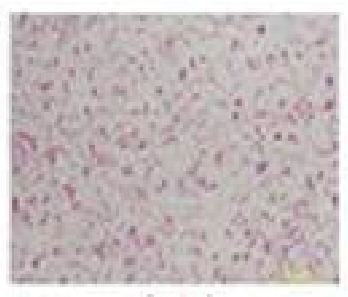

Contrel

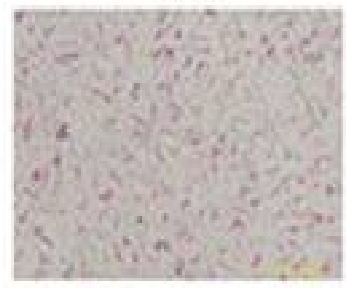

on M

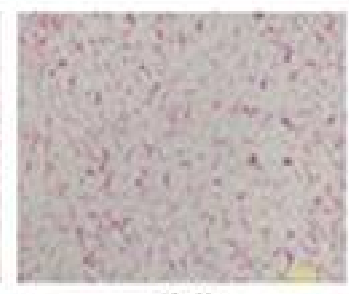

$10, \mu$

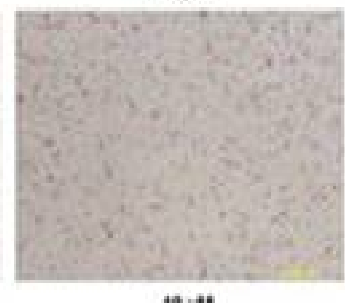

40 pll

D

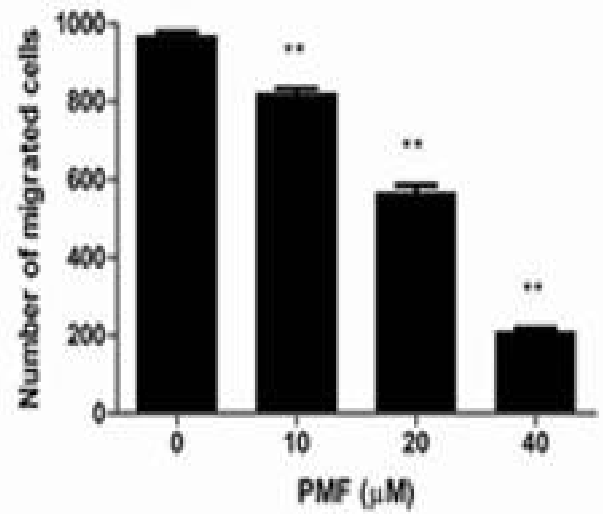

Figure 3: Effect of PMF on cell invasion ( $A$ and $B$ ) and migration ( $C$ and $D$ ) in A549 cell. Cell invasion and migration of A549 cells with PMF (10, 20 and $40 \mu \mathrm{M}, 48 \mathrm{~h})$ vs DMSO control were analysed by transwell with matrigel and transwell migration assay, respectively. Results are expressed as means \pm SD of three independent experiments in triplicates; ${ }^{* *} p<0.01$, compared to the control group 
PMF induces cell cycle arrest and apoptosis in A549 cells

To investigate whether the anti-proliferative effect of PMF is due to cell cycle arrest and/or apoptosis, we measured the effect of PMF on cell cycle progression and apoptotic response in A549 cell lines. Cells were treated with either increasing concentrations of PMF $(25,50$ and 75 $\mu \mathrm{M})$ or vehicle control (DMSO) for $48 \mathrm{~h}$ and cell cycle distributions were determined by $\mathrm{PI}$ staining and flow cytometry. Upon incubation

A
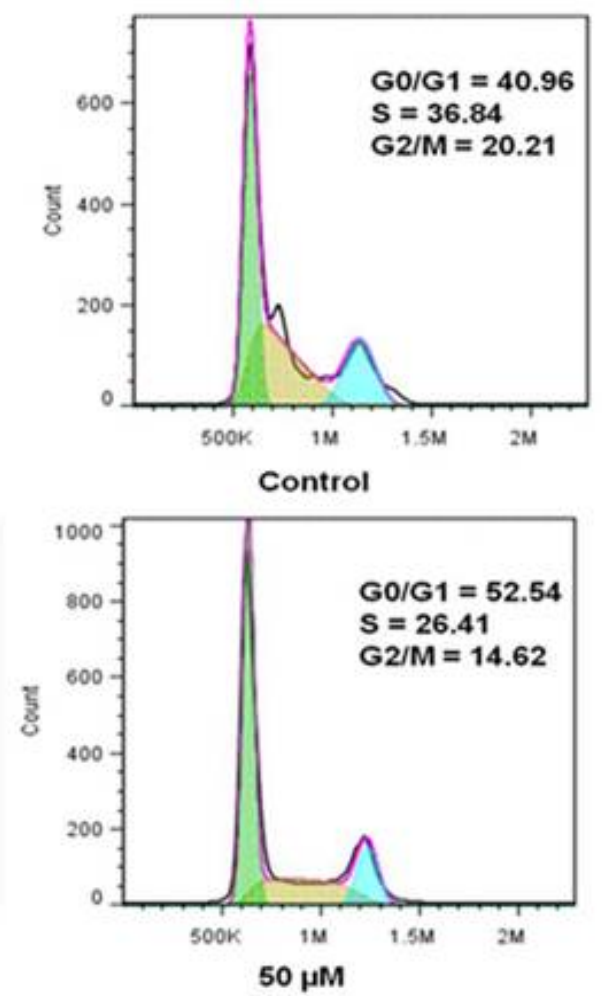

with PMF, A549 cells showed a dose-dependent accumulation in $\mathrm{G} 0 / \mathrm{G} 1$, indicating cell cycle arrest in this phase (Figure 4A and $\mathrm{B}$ ).

Apoptotic response was determined by both annexin $\mathrm{V}$ and $\mathrm{PI}$ staining and flow cytometry in A549 cells. After $48 \mathrm{~h}$ exposure to PMF, the cell apoptosis rate was increased from $21.16 \%$ to $51.93 \%$ with increasing concentrations of PMF $(25,50$ and $75 \mu \mathrm{M})$, compared with the control group (Figure $5 \mathrm{~A}$ and $\mathrm{B}$ ).
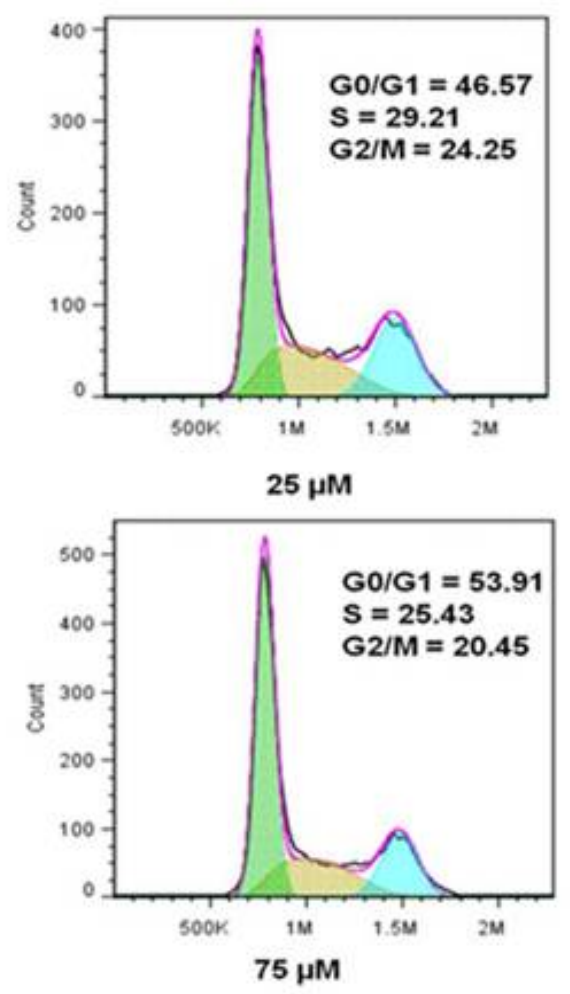

B

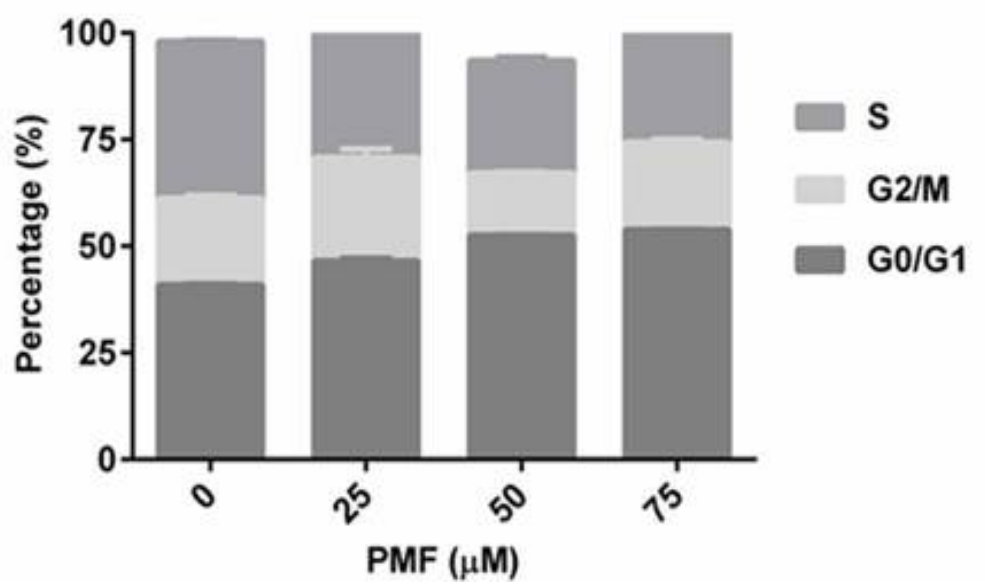

Figure 4: Effect of PMF on cell cycle of A549 cells. Results are expressed as mean \pm SD $(n=3) ;{ }^{* *} p<0.01$, compared to the control group. 
A $\bar{\alpha}$
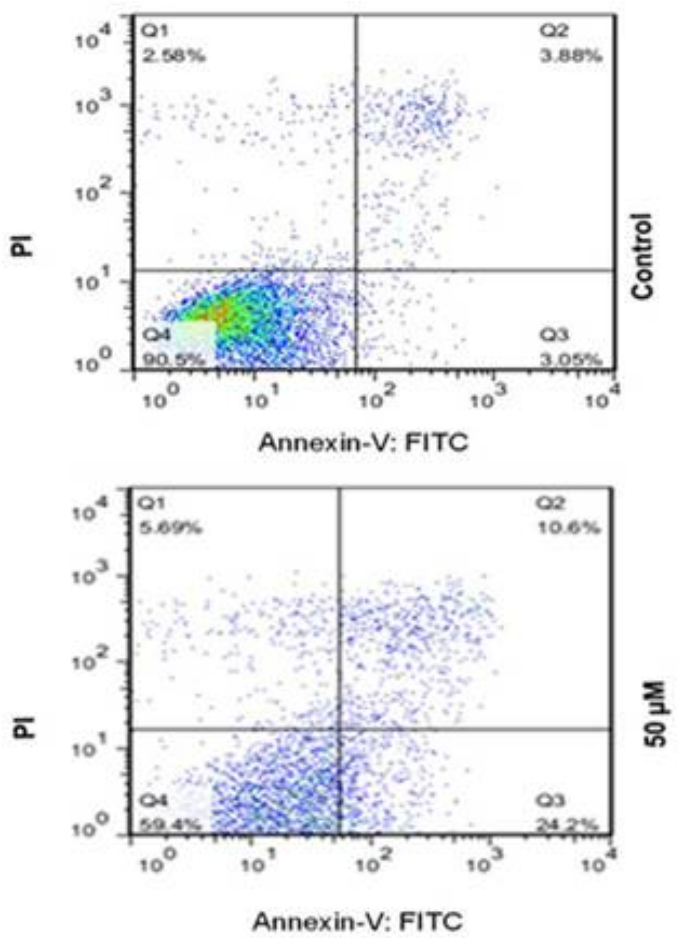

$\bar{\alpha}$

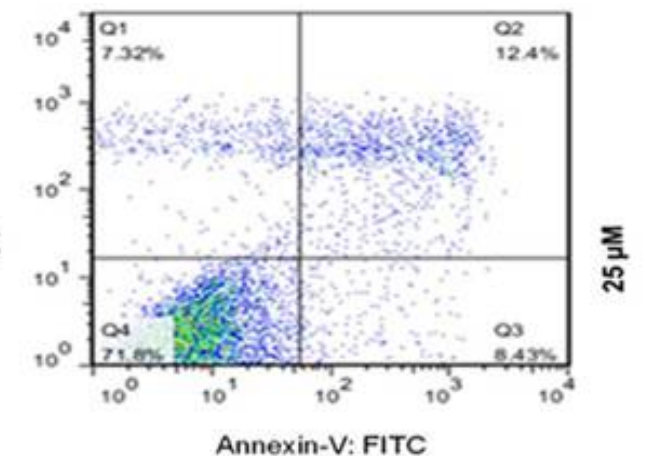

$\bar{\alpha}$

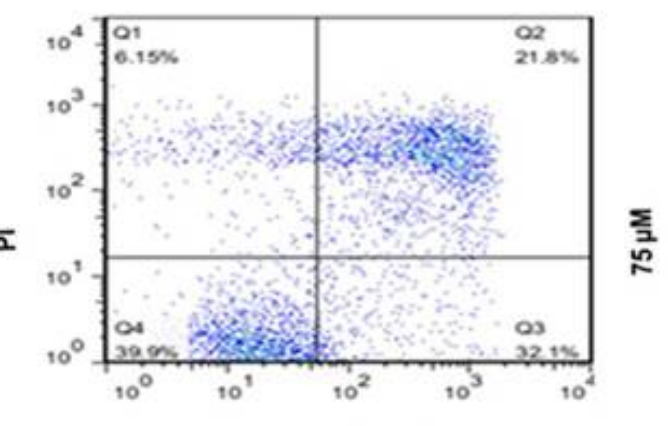

Annexin-V: FITC

B

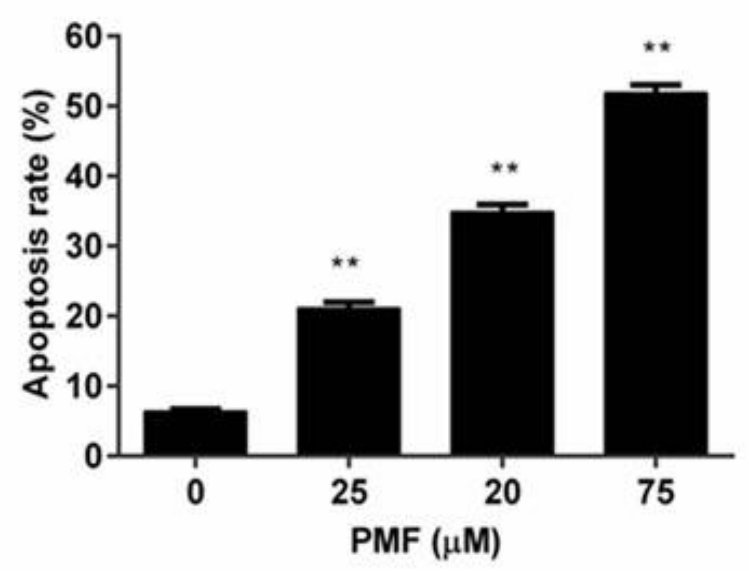

Figure 5: Effects of PMF on cell apoptosis of A549 cells. Results are expressed as mean $\pm \operatorname{SD}(n=3) ;{ }^{* *} p<0.01$, compared to the control group

\section{Protein expression levels of caspase-3, caspase-9, Bcl-2, Bax and COX-2}

Based on the results above, PMF inhibited the proliferation, migration and invasion of A549 cells and induced cell cycle arrest and apoptosis. To further explore the possible mechanisms, related proteins were detected by western blotting. As shown in Figure 6, it is interesting that the protein expression levels of caspase- 3 , caspase- 9 , and Bax were significantly up-regulated while Bacl-2 and COX-2 expressions were down-regulated. All these results indicated that the antiproliferation effect of PMF on the lung cancer cell might be related to promoting apoptosis proteins expression.

\section{DISCUSSION}

Apoptosis is a mode of animal cell death which is found in normal tissues and tumors. Apoptosis is essential for normal cell development and disturbance of apoptosis is one of the important reasons the development of tumors [12]. In our present study, we found that PMF could significantly inhibit the proliferation of human non-small cell lung cancer (A549 cell) and induce cell apoptosis, which suggested that the antiproliferation effect might be related to the enhancement of apoptosis.

Based on previous researching data, two alternative but overlapping pathways (the 
A

B
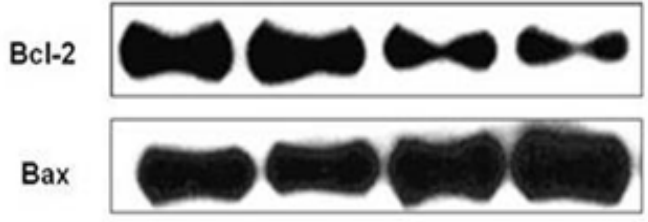

GAPDH

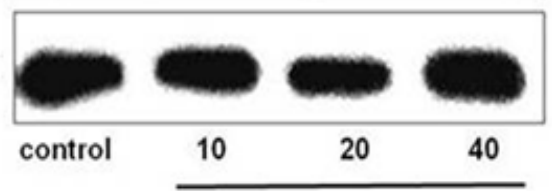

$\operatorname{PMF}(\mu \mathrm{M})$

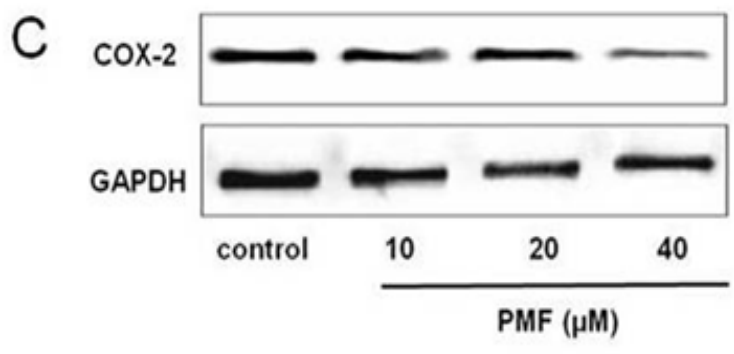

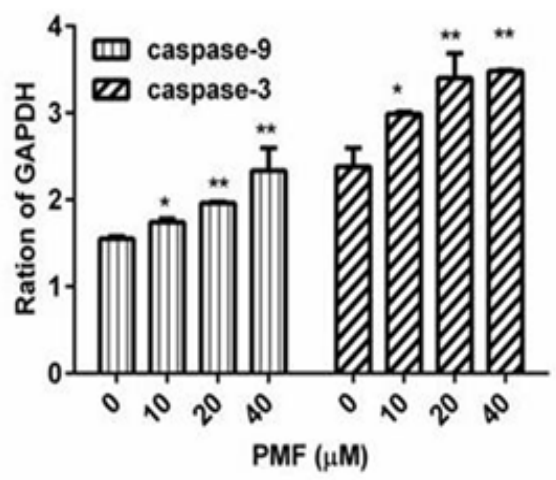
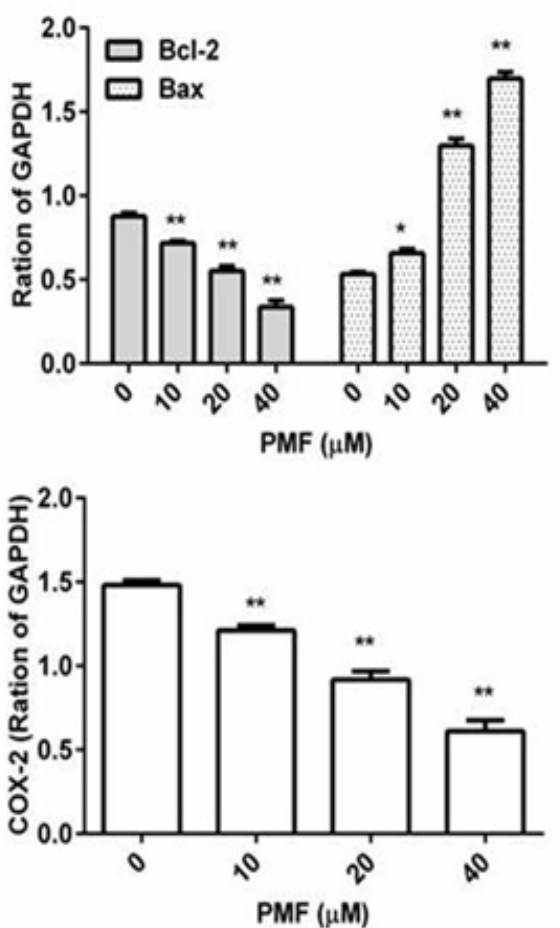

Figure 6: Effects of PMF on the protein expressions of caspase-3, caspase-9, Bcl-2, Bax, and COX-2 in A549 cells. GAPDH was used as the loading control; ${ }^{*} p<0.05,{ }^{* *} p<0.01$, compared to the control group

extrinsic and intrinsic pathways) cause cell apoptosis [13]. The extrinsic pathway can be activated by death receptors while the intrinsic pathway can be activated by the release of mitochondrial proteins $[14,15]$. Caspase- 8 has been demonstrated to play a crucial role in the activation of the extrinsic pathway and activated caspase- 9 is essential for activating the intrinsic pathway [13]. Both activated caspase-8 and caspase-9 can activate executioner caspases like caspase-3 which will activate death substrates and lead to cell death [16]. Caspase-3 is a key executor in the process of apoptosis and can hydrolyze specific protein substrates [17]. Caspase-3 and caspase- 9 expressions are often suppressed in various human cancers such as lung cancer, breast cancer, prostate cancer [1820].

In addition, the Bcl-2 protein family is an important regulator of the release of pro- apoptotic mitochondrial proteins. $\mathrm{Bcl}-2$ is a crucial anti-apoptotic protein and Bcl-2 overexpression contributes to cell survival. The upregulation of $\mathrm{Bcl}-2$ expression is found in nonsmall-cell lung cancer [22]. Furthermore, Bax is a pro-apoptotic member of Bcl-2 family and might act on the mitochondrial membrane [22]. Importantly, our result showed that PMF could enhance caspase-3, caspase-9 and Bax expressions while it decreases Bcl-2 expression. Thus, we found that PMF induced lung cancer cells apoptosis which might be related with activation of mitochondria-mediated apoptosis pathway.

Furthermore, cyclooxygenase 2 (COX-2) is a key enzyme in aberrant arachidonic acid metabolism and can catalyze the formation of prostaglandin E2 (PGE2) [23]. It has been reported that COX-2/ PGE2 can promote lung cancer invasion/migration and high expression of COX-2 
is often found in lung cancer [24]. In addition, previous data showed that PGE2activate Bcl-2 and interleukin-6 (IL-6) which can inhibit cell apoptosis and increase cancer cell invasion and migration, respectively [25]. In our present study, PMF significantly decreased cell invasion and migration, and reduced the protein expression level of COX-2 in A549 cells, which indicated that the inhibitory effect of PMF on lung cancer invasion and migration might be associated with decreased COX-2 expression in vitro.

\section{CONCLUSION}

The findings of this study show that PMF inhibits the proliferation, migration and invasion of human non-small cell lung cancer A549 cells, and also induces cell apoptosis. The mechanism may be related to the activation of the intrinsic mitochondrion-mediated apoptosis pathway by down-regulating the expression of $\mathrm{Bcl}-2$ and upregulating the expression of caspase-3, casepase-9 and Bax. Furthermore, PMF probably influences COX-2 expression and inhibits cell growth.

\section{DECLARATIONS}

\section{Conflict of Interest}

No conflict of interest associated with this work.

\section{Contribution of Authors}

The authors declare that this work was done by the authors named in this article and all liabilities pertaining to claims relating to the content of this article will be borne by them.

\section{REFERENCES}

1. Chen WQ, Zheng RS, Zhang SW, Zhao P, Zeng HM, Zou $X N$, He J. Annual report on status of cancer in China, 2010. Chin J Cancer Res 2014; 26: 48.

2. Zhou CC. Lung cancer molecular epidemiology in China: recent trends. Trans/ Lung Canc Res 2014; 3: 270.

3. Dempke WC, Suto T, Reck M. Targeted therapies for non-small cell lung cancer. Lung Cancer 2010; 67: 257274.

4. Liu Q, Du SY, Ci R, Guo QL. Survey of Tibetan medicine Pangxiejia. Western J Tradit Chin Med 2014; 27: 138140.

5. Baima S. Drug Specifications. Tibetan Medicine. China: The Ministry of Public Health; 1997.

6. Committee CP. Drug Specifications. Tibetan Medicine. China: The Ministry of Public Health; 1995.

7. Wang QS, Yang L, Cui WY, Chen L, Jiang YH. Antiinflammatory and anti-nociceptive activities of methanol extract from aerial part of Phlomis younghusbandii Mukerjee. PloS one 2014; 9: 89149.

8. Zhang C, Li MX, He XR, Jia ZP. Analgesic and antiinflammatory activities of Phlomis younghusbandii. West Chin J Pharm Sci 2011; 26: 135-137.

9. Du BZ, Ren Z, Ciwang ZM, Deji YZ, Wang JL.Vitro Antibacterial Activity of Extractum Phlomis younghunsbandii Mukerjee Against Pseudomonas aeruginosa. J Tibet Univ 2010; 25: 27-30

10. Li Q, Yang SR, Yang SL, Xin FZ, Wang MJ. Antiinflammatory activity of phlomisoside $F$ isolated from Phlomis younghubandii Mukerjee. Int Immunopharmacol 2015; 28: 724-730.

11. Zhao B, Liang $H, Y u Y$, Dong $X$. A new furanolabdane diterpene glycoside from Phlomis younghusbandii Mukerjee. Acta Pharm Sin 2009; 44: 60-62.

12. Gerl R, Vaux DL. Apoptosis in the development and treatment of cancer. Carcinogenesis 2005; 26: 263-270.

13. Shivapurkar N, Reddy J, Chaudhary PM Gazdar AF. Apoptosis and lung cancer: a review. J Cell Biochem2003; 88: 885-898.

14. Thorburn A. Death receptor-induced cell killing. Cell Signal 2004; 16: 139-144.

15. Yon JH, Daniel-Johnson J, Carter L, Jevtovic-Todorovic $\checkmark$. Anesthesia induces neuronal cell death in the developing rat brain via the intrinsic and extrinsic apoptotic pathways. Neuroscience 2005; 135: 815-827.

16. Boatright KM, Salvesen GS. Mechanisms of caspase activation. Curr Opin Cell Biol 2003; 15: 725-731.

17. Porter AG, Jänicke RU. Emerging roles of caspase-3 in apoptosis. Cell Death Differ 1999; 6: 99-104.

18. Devarajan E, Sahin AA, Chen JS, Krishnamurthy RR, Aggarwal N, Brun AM, Sapino A, Zhang F, Sharma D, Yang $\mathrm{XH}$. Down-regulation of caspase 3 in breast cancer: a possible mechanism for chemoresistance. Oncogene 2002; 21: 8843-8851.

19. Du A, Zhao B, Yin D, Zhang SL, Miao JY. Safrole oxide induces apoptosis by activating caspase-3,-8, and-9 in A549 human lung cancer cells. Bioorg Med Chem Lett 2006; 16: 81-83.

20. Winter RN, Kramer A, Borkowski A, Kyprianou N. Loss of caspase-1 and caspase-3 protein expression in human prostate cancer. Canc Res 2001; 61: 1227-1232.

21. Fontanini G, Vignati S, Bigini D, MussiA, LucchiM, Angeletti CA, Basolo F, Bevilacqua G. Bcl-2 protein: a prognostic factor inversely correlated to $p 53$ in nonsmall-cell lung cancer. Brit J Cancer 1995; 71: 1003.

22. Hong YS, Ham YA, Choi JH, Kim J. Effects of allyl sulfur compounds and garlic extract on the expressions of Bcl2, Bax, and p53 in non-small cell lung cancer cell lines. ExpMol Med 2000; 32: 127-134.

23. Greenhough A, Smartt HJ, Moore AE, Roberts HR, Williams AC, Paraskeva C, Kaidi A. The COX-2/PGE2 pathway: key roles in the hallmarks of cancer and adaptation to the tumour microenvironment. Carcinogenesis 2009; 30: 377-386.

24. Hida $T$, Yatabe Y, Achiwa H, MuramatsuH, Kozaki K, Nakamura S, Ogawa M, Mitsudomi T, SugiuraT,

Trop J Pharm Res, July 2016; 15(7): 1420 
Takahashi T. Increased expression of cyclooxygenase 2 occurs frequently in human lung cancers, specifically in adenocarcinomas. Cancer Res 1998; 58: 3761-3764.
25. Fosslien E. Molecular pathology of cyclooxygenase-2 in neoplasia. AnnClinLab Sci 2000; 30: 3-21 